\title{
Cultivares de morango de dia neutro: produção em função de doses de nitrogênio durante o verão
}

\author{
Rosana F Otto ${ }^{1}$; Rodrigo K Morakami²; Marie Y Reghin ${ }^{1}$; Eduardo F Caíres ${ }^{3}$ \\ ${ }^{1}$ UEPG-DEFITO, Av. Carlos Cavalcanti, 4748, 84030-900 Ponta Grossa-PR; ' 2 Eng. Agrônomo; ${ }^{3}$ UEPG-DESOLO, Av. Carlos Cavalcanti, \\ 4748, 84030-900 Ponta Grossa-PR; rfotto@uepg.br
}

\begin{abstract}
RESUMO
O morangueiro é uma espécie cuja área de cultivo aumenta a cada ano, devido à introdução de cultivares melhor adaptadas às condições climáticas das diferentes regiões brasileiras. Em experimento realizado entre outubro de 2003 e maio de 2004, em Ponta Grossa, avaliouse a produção de frutos e a emissão de estolões em três cultivares de morangueiro de dia neutro (Aromas, Diamante e Seascape), submetidas a diferentes formulações de fertirrigação. O delineamento experimental foi blocos casualizados, com três repetições, parcelas subdivididas (4 adubações x 3 cultivares) e seis plantas na área útil da subparcela. As adubações testadas foram calculadas a partir da formulação $0,12 \mathrm{~g} \mathrm{~m}^{-2}$ de $\mathrm{N}, 0,23 \mathrm{~mL} \mathrm{~m}^{-2}$ de $\mathrm{Pe} 0,11 \mathrm{~g} \mathrm{~m}^{-2}$ de $\mathrm{K}$ na fase vegetativa e $0,08 \mathrm{~g} \mathrm{~m}^{-2}$ de N, $0,045 \mathrm{~mL} \mathrm{~m}^{-2}$ de Pe $0,39 \mathrm{~g} \mathrm{~m}^{-2} \mathrm{de} \mathrm{K}$ para a fase reprodutiva $\left(\mathrm{A}_{1 \mathrm{~N}}\right)$ e corresponderam à dose $\mathrm{A}_{1 \mathrm{~N}}$ e a zero, $1 / 3 \mathrm{e}$ $2 / 3$ do $N$ presente em $A_{1 N}$, tanto na fase vegetativa como na fase reprodutiva. As cultivares foram transplantadas em outubro de 2003, em estufa tipo arco com laterais abertas. Avaliou-se número de frutos (NFP) e de estolões (NEP) por planta, produtividade e massa fresca do fruto (MFF). Verificou-se que $\mathrm{A}_{\text {oN }}$ favoreceu a formação de maior $\mathrm{NEP}$ em relação à $\mathrm{A}_{2 / 3 \mathrm{~N}}$, sem diferir significativamente de $\mathrm{A}_{1 \mathrm{~N}} \mathrm{e}_{1 / 3 \mathrm{~N}}$. Os distintos níveis de $\mathrm{N}$ não alteraram significativamente a produtividade, NFP e MFF. Já as cultivares diferiram significativamente entre si para todas essas características. A cultivar Diamante apresentou MFF (16,2 g) significativamente mais alta que as demais, seguida pelas cultivares Aromas (14,3 g) e Seascape (12,2 g). A cultivar Seascape apresentou produtividade superior à cultivar Aromas, respectivamente 38,1 e 28,4 $\mathrm{tha}^{-1}$, e semelhante à cultivar Diamante $\left(31,7 \mathrm{t} \mathrm{ha}^{-1}\right)$. Recomenda-se a cultivar Seascape quando o mercado não exigir frutos maiores que $12 \mathrm{~g}$ de massa. Caso a exigência seja por frutos maiores, recomenda-se a cultivar Diamante.
\end{abstract}

Palavras chave: Fragaria X ananassa Duch., fertirrigação, estolão.

\begin{abstract}
Day-neutral strawberry cultivars: summer yield in function of nitrogen rates
\end{abstract}

The strawberry plant is one of the horticultural species whose cultivation area increases each year, due to the introduction of better adapted cultivars to the climatic conditions of various Brazilian regions. An experiment was carried out between October 2003 and May 2004, in Ponta Grossa, to evaluate the fruit production and stolon emission of three Day-neutral cultivars (Aromas, Diamante and Seascape), submitted to different formulations of fertigation. The experimental design was of randomized blocks, with three replications, arranged in a split plot scheme (4 fertilizations x 3 cultivars), with 6 plants in the subplot useful area. Fertilizations were calculated from the formulation $0.12 \mathrm{~g} \mathrm{~m}^{-2}$ nitrogen $(\mathrm{N}), 0.23 \mathrm{~mL} \mathrm{~m}^{-2}$ phosphorus $(\mathrm{P})$ and $0.11 \mathrm{~g} \mathrm{~m}^{-2}$ potassium $(\mathrm{K})$ in vegetative phase and $0.08 \mathrm{~g} \mathrm{~m}^{-2} \mathrm{~N}$, $0.045 \mathrm{~mL} \mathrm{~m}^{-2} \mathrm{P}$ and $0.39 \mathrm{~g} \mathrm{~m}^{-2} \mathrm{~K}$ for reproductive phase, corresponding to $A_{1 N}$ rate and zero, $1 / 3$ and $2 / 3 \mathrm{~N}$ rates used in $A_{1 N}$, as much for vegetative as reproductive phase. The cultivars were transplanted in October 2003 in a greenhouse with open laterals. The numbers of fruits (NFP) and stolons (NEP) of each plant, productivity and fruit mean weight (MFF) were evaluated. $A_{0 N}$ rate favoured highest stolon emission compared to $\mathrm{A}_{2 / 3 \mathrm{~N}}$, without differing significantly from $\mathrm{A}_{1 \mathrm{~N}}$ and $\mathrm{A}_{1 / 3 \mathrm{~N}}$. Rates of $\mathrm{N}$ did not modify significantly the productivity, NFP and MFF. However, cultivars differed significantly from all three for all features evaluated. Cultivar Diamante had highest MFF (16.2 g) compared to the others, followed by cultivars Aromas (14.3 g) and Seascape (12.2 g). Cultivar Seascape had highest productivity to cultivar Aromas, respectively 38.1 and $28.4 \mathrm{t} \mathrm{ha}^{-1}$, and similar to cultivar Diamante $\left(31.7 \mathrm{t} \mathrm{ha}^{-1}\right)$. Cultivar Seascape is recommended when the market does not demand bigger fruits than $12 \mathrm{~g}$ of weight. If the requirement is of bigger fruits, cultivar Diamante is recommended.

Keywords: Fragaria X ananassa Duch., fertigation, stolon.

\section{(Recebido para publicação em 11 de julho de 2008; aceito em 7 de maio de 2009) (Received in July 11, 2008; accepted in May 7, 2009)}

\begin{abstract}
$\mathrm{O}$ frutos do morango (Fragaria X ananassa Duch.) são mundialmente apreciados, sendo a espécie de maior expressão econômica entre as pequenas frutas vermelhas. É um produto com potencial de aumento de consumo. Um exemplo é o volume de morango comercializado na CEASA-PR. Em 2001, foram $2318 \mathrm{t}$, movimentando $\mathrm{R} \$$ 5.246.721,50. Em 2006, o volume comercializado foi de $5188 \mathrm{t}$, com um montante de R\$15.246.675,00 envolvidos na comercialização (CEASA-PR, 2007). Se-
\end{abstract}

gundo Reichert \& Madail (2003), a produção brasileira em 1999 foi superior a 90 mil $\mathrm{t} \mathrm{ano}^{-1}$, com aproximadamente 3600 ha de área plantada. No contexto nacional, os estados maiores produtores de morango são Minas Gerais (32,3\%), São Paulo $(31,4 \%)$ e Rio Grande do Sul $(16,5 \%)$. Segundo a SEAB-PR (2007), no Paraná foi cultivada uma área de 435,6 ha de morango produzindo, em média, $11 \mathrm{mil} \mathrm{t}$ de frutos, para a safra 2002/2003.

Para acompanhar esse mercado em expansão, o produtor de morangos tem procurado investir em tecnologia visando o aumento do rendimento da cultura. Ao optar por mudas de qualidade, como as originárias do Chile e da Argentina, a partir de 1997 o produtor permitiu que a produtividade média passasse de 25 para mais de $30 \mathrm{t} \mathrm{ha}^{-1}$ (Santos \& Medeiros, 2003). Além disso, o período de produção de frutos vem aumentando devido à produção no período de entressafra, possível com cultivares de Dia Neutro (DN). De acordo com Manakasem \& Goodwin (2001), o florescimento nas 
cultivares de DN é relativamente insensível ao comprimento do dia em regimes de temperatura dia/noite de $21 / 16^{\circ} \mathrm{C}$, mas a variação na temperatura e a cultivar poderão modificar grandemente esse efeito.

No sul do Brasil, a utilização de cultivares de DN tem acontecido na primavera/verão de regiões de altitude e com verão ameno e também durante o inverno. As cultivares mais conhecidas são Aromas, Diamante e Seascape, as quais apresentam semelhança quanto às características físico-químicas dos frutos, não havendo preferência entre consumidores quanto ao sabor (Ferrari et al., 2004). No entanto, quanto à aparência dos frutos, a cultivar Aromas é a preferida e a cultivar Seascape é considerada a menos atrativa, possivelmente devido ao menor tamanho do fruto em relação às cultivares Aromas e Diamante (Ferrari etal., 2004).

Além da ação de fatores ambientais atuando sobre a fisiologia da cultura, a adubação é outro fator que interfere na produção e qualidade dos frutos. Para as cultivares de DN, em especial, além da resposta da planta ser pouco conhecida nas regiões produtoras brasileiras, tampouco se conhece a adubação mais adequada. Caso os conhecimentos sobre a necessidade de nutrientes e as tecnologias de fertilização sejam melhorados, será possível manter uma produção satisfatória de frutos de qualidade com um incremento mínimo de nutrientes (Tagliavini et al., 2005).

É conhecido que o nitrogênio (N) exerce grande influência no desenvolvimento vegetativo, na produtividade e na qualidade do morango. A deficiência diminui o vigor das plantas e a produtividade, mas melhora a qualidade organoléptica do morango (Passos, 1999). O excesso aumenta o vigor das plantas, reduz a indução floral, atrasa a floração e reduz a qualidade dos frutos em relação ao conteúdo de açúcares, textura e coloração, além de favorecer a ocorrência de deformações e do mofo cinzento (Passos, 1999). Na fase de emissão de estolões e na produção de mudas, Tworkoski et al. (2001) verificaram que o crescimento vegetativo mudou em resposta ao aumento das doses de $\mathrm{N}$ testadas nas plantasmãe, diminuindo o comprimento médio do estolão e aumentando o número de estolões e de mudas, enquanto mantiveram o comprimento total de estolão. $\mathrm{O}$ resultado foi um aumento na densidade de mudas por planta-mãe.

As doses exatas de $\mathrm{N}$ que devem ser fornecidas em fertirrigações têm sido tema de estudos em outros países. Na Flórida, Hochmuth et al. (1996) avaliaram doses entre 0,28 e $1,40 \mathrm{~kg} \mathrm{~N}^{-1} \mathrm{dia}^{-1}$ (50 a 250 $\mathrm{kg} \mathrm{ha}^{-1}$ ciclo $^{-1}$ ) em dois experimentos, sendo o primeiro com as cultivares Oso Grande e Sweet Charlie e, o segundo, com as cultivares Oso Grande e Seascape. Verificaram que a produção total de frutos aumentou quando as doses de $\mathrm{N}$ aumentaram até $0,54 \mathrm{~kg} \mathrm{ha}^{-1} \mathrm{dia}^{-1}$, para o primeiro experimento. Porém, a fertilização nitrogenada não afetou a produção final no segundo experimento. Já Tagliavini et al. (2005), na Itália, utilizaram $55 \mathrm{~kg} \mathrm{ha}^{-1}$ de $\mathrm{N}$ no cultivo dos morangueiros, cultivares Idea e Marmolada. Para ambas cultivares, a taxa de crescimento aumentou depois do florescimento até o final da maturação dos frutos e a taxa de absorção dos nutrientes foi menor no outono que na primavera. A extração total de nutrientes pelas plantas ficou entre 78 e 91 $\mathrm{kg} \mathrm{ha}^{-1}$ de N.

Para genótipos de DN, cultivados em regiões com verão ameno, supõe-se que um melhor controle dos níveis de nitrogênio fornecido à cultura possa influenciar positivamente no desenvolvimento da planta, sem intensificar o estímulo para crescimento vegetativo já exercido pela condição climática favorável. A região metropolitana de Curitiba e os Campos Gerais-PR utiliza cultivares de DN para produção de frutos no período de verão, mas até o momento não se conhece o genótipo e adubação mais adequados para cultivo na região.

O objetivo deste trabalho foi avaliar a produção de frutos e emissão de estolões das cultivares de dia neutro Seascape, Diamante e Aromas durante o verão, utilizando a fertirrigação como meio de controlar o fornecimento de nitrogênio, em doses e fases de desenvolvimento diferentes.

\section{MATERIAL E MÉTODOS}

O experimento foi conduzido na área experimental da UEPG em Ponta Grossa-

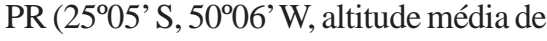
$950 \mathrm{~m}$ ), durante o ano agrícola de 2003/ 2004. O clima da região, segundo a classificação de Köppen, é subtropical úmido mesotérmico ( $\mathrm{Cfb}$ ), com temperatura média do mês mais frio abaixo de $18^{\circ} \mathrm{C}$ (mesotérmico), verões frescos e temperatura média do mês mais quente abaixo de $22^{\circ} \mathrm{C}$. A precipitação e temperatura média anual são $1700 \mathrm{~mm}$ e $20^{\circ} \mathrm{C}$, respectivamente. O solo foi classificado (EMBRAPA, 1999) como Cambissolo háplico Tb Distrófico e de textura argilosa. A análise química do solo apresentou valores de 5,4 de $\mathrm{pH}$ em $\mathrm{CaCl}_{2}$ 0,01M; 5,35 c mol c dm ${ }^{-3}$ de H + AL; 0,0 c mol c $\mathrm{dm}^{-3}$ de AL; 7,5 c mol c dm ${ }^{-3}$ de $\mathrm{Ca}+\mathrm{Mg}$; 4,5 $\mathrm{c} \mathrm{mol} \mathrm{c} \mathrm{dm}{ }^{-3}$ de Ca; 0,34 c mol c dm ${ }^{-3}$ de $\mathrm{K} ; 20,1 \mathrm{mg} \mathrm{dm}^{-3}$ de P (Mehlich) e $23 \mathrm{~g}$ $\mathrm{dm}^{-3}$ de $\mathrm{C}$, sendo os resultados obtidos no Laboratório de Fertilidade dos Solos da UEPG.

Instalou-se o experimento em estufa do tipo arco, no sentido leste-oeste, com estrutura em ferro galvanizado, tendo dimensões de 6,40 m de largura e 37,5 m de comprimento, coberta com filme plástico transparente de $0,15 \mathrm{~mm}$ de espessura e tendo as laterais totalmente abertas. O delineamento experimental foi blocos casualizados, com os tratamentos distribuídos em parcelas subdivididas, com três repetições. $\mathrm{O}$ fator principal foi adubação nitrogenada (quatro níveis) e, o secundário, cultivares (Aromas, Diamante, Seascape). As adubações avaliadas foram determinadas a partir da adubação recomendada (testemunha $\left.\left(\mathrm{A}_{1 \mathrm{~N}}\right)\right)$ aos produtores de morango que plantam no verão, na região metropolitana de Curitiba e arredores, utilizando cultivares de dia neutro. Para cada fertirrigação realizada a solução continha $0,12 \mathrm{~g} \mathrm{~m}^{-2}$ de N, 0,23 $\mathrm{mL} \mathrm{m}^{-2}$ de Pe 0,11 g $\mathrm{m}^{-2}$ de $\mathrm{K}$ na fase vegetativa e $0,08 \mathrm{~g} \mathrm{~m}^{-2}$ de $\mathrm{N}, 0,045 \mathrm{~mL} \mathrm{~m}^{-2}$ de Pe $0,39 \mathrm{~g} \mathrm{~m}^{-2}$ de K para a fase reprodutiva, segundo o $\mathrm{Eng}^{\circ}$ Agrônomo Hugo Reis Vidal (comunicação pessoal, 2003). A partir da adubação testemunha $\left(\mathrm{A}_{1 \mathrm{~N}}\right)$, foram calculadas as demais adubações, alterando-se as doses de nitrogênio de cada formulação em zero $\left(A_{0 N}\right), 1 / 3\left(A_{1 / 3 N}\right)$ e $2 / 3\left(A_{2 / 3 N}\right)$ da dose de nitrogênio utilizada em $\mathrm{A}_{1 \mathrm{~N}}$, tanto para a fase vegetativa como para a fase reprodutiva da cultura. As quantidades recomendadas de fósforo e potássio foram mantidas. 
O preparo do solo constou de levantamento de canteiros com 4,5 m de comprimento e 0,6 $\mathrm{m}$ de largura para cada parcela. A adubação química de base foi realizada sete dias antes do transplante das mudas, utilizando-se a formulação NPK (4-14-08) incorporada nos canteiros, na proporção de $100 \mathrm{~g} \mathrm{~m}^{-2}$ [adubação de base recomendada aos produtores que estão cultivando morango durante o período de verão, segundo o Eng $^{\circ}$ Agrônomo Hugo Reis Vidal (comunicação pessoal, 2003)]. A fertirrigação foi aplicada por gotejamento, distribuída em duas linhas por canteiro, com espaçamento de 0,30 m entre emissores e 0,30 m entre linhas. A vazão em cada fertirrigação foi de $50 \mathrm{~L}$ parcela $^{-1}$ hora $^{-1}$, sendo os 15 minutos iniciais apenas com água, outros $30 \mathrm{mi}$ nutos com nutrientes específicos de cada tratamento e, os 15 minutos finais, novamente apenas com água. Cada parcela do experimento possuía um registro de liberação ou não da solução nutritiva, que eram abertos quando a adubação era a especificada para a parcela. Após a implantação da cultura, as fertirrigações foram realizadas duas ou três vezes por semana, dependendo da demanda hídrica durante todo o ciclo de cultivo, em um total de 46 fertirrigações.

As mudas foram transplantadas em 21 de outubro de 2003, em canteiros com 4,5 m de comprimento e 0,6 $\mathrm{m}$ de largura, no espaçamento $0,30 \times 0,30 \mathrm{~m}$, caracterizando por unidade experimental duas linhas com cinco plantas em cada. $\mathrm{O}$ mulching preto de agrotêxtil $\left(40 \mathrm{~g} \mathrm{~m}^{-2}\right)$ foi colocado 17 dias após o transplante (DAT) e fixado em torno do canteiro com terra. Fez-se uma aplicação de Pirimicarb (2 g em 20 L) 59 DAT para o controle de pulgão, quando a população atingiu o nível de controle. Foram feitas aplicações para o controle de ácaros e pulgões com Thiamethoxam ( $5 \mathrm{~g}$ em $20 \mathrm{~L}$ ) 102 e 201 DAT. Foram feitas ainda quatro aplicações foliares de cálcio e boro, iniciando-se 171 DAT, com intervalos de sete dias, devido ao aparecimento de sintomas de deficiência nas folhas mais novas. A deficiência foi controlada com a utilização do produto Sett $\left(\mathrm{CaCl}_{2}\right.$ $\mathrm{H}_{3} \mathrm{BO}_{3}, 4$ mL em 6L).

Realizou-se contagem do número de estolões e peso fresco de frutos com pelo menos $60 \%$ de coloração vermelha, para as seis plantas centrais de cada parcela. A colheita de estolões iniciouse em 16 de dezembro e terminou em meados de abril e início de maio para as cultivares Aromas e Diamante, respectivamente. Para a cultivar Seascape a colheita de estolões finalizou na primeira semana de março para os tratamentos $A_{1 N}$ e $A_{0 N}$ e, no final de março, para $A_{1 / 3 N}$ e $\mathrm{A}_{2 / 3 \mathrm{~N}}$. A colheita de frutos foi realizada entre 13 de janeiro e 31 de maio de 2004. Os frutos foram contados e pesados em balança de precisão com duas casas digitais e, os estolões, contados individualmente, depois de retirados da planta.

Os dados obtidos no experimento foram submetidos à análise de variância, utilizando-se para comparação de médias o teste de Tukey, a 5\% de probabilidade, para determinar o efeito das doses de $\mathrm{N}$, realizar a comparação entre as cultivares e verificar a ocorrência de interação entre doses de $\mathrm{N}$ e cultivares. A análise de regressão foi realizada para a determinação de modelos que representem a resposta da fertilização sobre as características estudadas quando o efeito das doses de $\mathrm{N}$ foi significativo estatisticamente. Para a interação não significativa, o efeito das doses de $\mathrm{N}$ foi avaliado entre as cultivares.

\section{RESULTADOS E DISCUSSÃO}

Não houve interação significativa entre adubação e cultivares para nenhumas das características avaliadas e a fertilização com $\mathrm{N}$ dentro das doses estudadas apresentou significância somente para número de estolões planta ${ }^{-1}(\mathrm{Ta}-$ bela 1), sendo realizada a análise de regressão. No entanto, a análise não indicou significância para as equações linear e polinomiais para nenhuma das três cultivares. Ainda que se tenha encontrado ajuste para o modelo de Richard para as cultivares Seascape, Diamante e Aromas, esse modelo não descreve o comportamento biológico no campo do efeito da fertilização sobre a produção de estolões. Desta forma, as médias foram comparadas dentro dos diferentes níveis de fertilização. Verificou-se que $\mathrm{A}_{0 \mathrm{~N}}$ favoreceu a formação de maior número de estolões planta ${ }^{-1}$ em relação à $\mathrm{A}_{2 / 3 \mathrm{~N}}$, sem diferir significativamente de
$\mathrm{A}_{1 \mathrm{~N}}$ e $\mathrm{A}_{1 / 3 \mathrm{~N}}$. Em relação aos genótipos, a cultivar Seascape produziu menor número de estolões planta ${ }^{-1}$ comparada às outras cultivares, sendo que a cultivar Aromas apresentou os maiores valores. A resposta da planta parece estar mais relacionada às características da cultivar. Isto porque os resultados demonstram que as doses de $\mathrm{N}$ que vêm sendo utilizadas em cultivos comerciais no sudeste do Paraná $\left(\mathrm{A}_{1 \mathrm{~N}}\right)$, isto é, 0,12 e 0,08 $\mathrm{g} \mathrm{N} \mathrm{m}^{-2}$ fertirrigação para fase vegetativa e reprodutiva, respectivamente, apresentaram respostas semelhantes para a ausência $\left(\mathrm{A}_{0 \mathrm{~N}}\right)$ ou redução até um terço dessa adubação $\left(\mathrm{A}_{1 / 3}\right)$ para produção de estolões planta-1 (Tabela 1). A resposta aos níveis de $\mathrm{N}$ pode variar dependendo do genótipo avaliado. Tworkoski et al. (2001) estudaram o efeito do $\mathrm{N}$ no crescimento de estolões e mudas em quatro genótipos de morango e verificaram que os genótipos diferiram quanto ao tamanho da planta, produção de estolões e de mudas. O número de estolões e a densidade de mudas aumentaram com o aumento do $\mathrm{N}$ para todos os genótipos testados, especialmente o Q18. Também, para esse genótipo, o número de mudas por $100 \mathrm{~cm}$ de comprimento do estolão aumentou com o aumento das doses de $\mathrm{N}$.

Além do número de estolões emitidos pela planta, é importante conhecer a duração do período de emissão de estolões durante o ciclo da cultura. $\mathrm{Na}$ primeira colheita de estolões (16 de dezembro de 2003), as três cultivares avaliadas apresentaram estolões, porém a cultivar Seascape tinha, em média, apenas $20 \%$ do número total de estolões verificados nas cultivares Aromas e Diamante. Ao longo do ciclo, esse valor aumentou, porém sem ultrapassar 50\% do total das outras cultivares.

Além disso, a formação de estolões se encerrou primeiramente para a cultivar Seascape. Para as cultivares Aromas e Diamante, o término da emissão de estolões não foi diferente entre as adubações utilizadas. Enquanto as plantas da cultivar Aromas encerraram a emissão de estolões em 15 de abril e, as da cultivar Diamante, em 06 de maio de 2004, na cultivar Seascape não houve mais emissão de estolões nas adubações $A_{1 N}$ e $A_{0 N}$ a partir já da primeira semana de 
Tabela 1. Número de estolões por planta, produtividade, número de frutos por planta e massa fresca média de frutos de três cultivares de morango de dia neutro, submetidas a quatro níveis de fertirrigação, em cultivo no verão (number of stolons per plant, yield, number of fruits per plant, average fruit fresh mass of three day-neutral strawberry cultivars, growing with four fertigation levels, in summer crop). Ponta Grossa, UEPG, 2003/2004.

\begin{tabular}{|c|c|c|c|c|}
\hline Tratamentos $^{2}$ & NEP $^{1}$ & $\begin{array}{l}\text { Produtividade } \\
\left(\mathrm{t} \mathrm{ha}^{-1}\right)\end{array}$ & NFP $^{1}$ & $\operatorname{MFF}^{1}(g)$ \\
\hline$\overline{\mathrm{A} 1 \mathrm{~N}}$ & $26,2 a b$ & $33,9 \mathrm{a}$ & $21,8 \mathrm{a}$ & $14,1 \mathrm{a}$ \\
\hline AON & 30,4 a & 35,5 a & $23,7 \mathrm{a}$ & $13,7 \mathrm{a}$ \\
\hline $\mathrm{A} 1 / 3 \mathrm{~N}$ & $26,0 \mathrm{ab}$ & $27,5 \mathrm{a}$ & $18,5 \mathrm{a}$ & $15,1 \mathrm{a}$ \\
\hline $\mathrm{A} 2 / 3 \mathrm{~N}$ & $22,5 \quad b$ & $34,0 \mathrm{a}$ & $23,7 \mathrm{a}$ & $14,7 \mathrm{a}$ \\
\hline C.V. (\%) & 16,3 & 35,5 & 38,7 & 10,2 \\
\hline Seascape & $11,7 \quad \mathrm{c}$ & $38,1 \mathrm{a}$ & $28,1 \mathrm{a}$ & $12,2 \quad c$ \\
\hline Diamante & $29,5 \quad b$ & $31,7 a b$ & $18,3 \quad b$ & $16,2 \mathrm{a}$ \\
\hline Aromas & 37,7 a & $28,4 \quad b$ & $19,4 \quad b$ & $14,3 \mathrm{~b}$ \\
\hline C.V. (\%) & 26,5 & 20,7 & 19,9 & 7,0 \\
\hline F (adubação) & 5,3 * & $0,9 \mathrm{~ns}$ & $0,7^{\mathrm{ns}}$ & $1,4^{\mathrm{ns}}$ \\
\hline F (cultivar) & $43,7^{* *}$ & 6,3 ** & 18,3 * * & 47,2 ** \\
\hline F (interação) & $1,0 \mathrm{~ns}$ & $1,0 \mathrm{~ns}$ & $1,5 \mathrm{~ns}$ & 0,8 ns \\
\hline
\end{tabular}

Médias seguidas da mesma letra nas colunas não diferem significativamente entre si, teste de Tukey, $\mathrm{p}<0,05$ (means followed by the same letter in the line do not differ significantly from each other, Tukey test, $\mathrm{p}<0.05$ ); ${ }^{1} \mathrm{NEP}=$ número de estolões por planta (number of stolons per plant); $\mathrm{NFP}=$ número de frutos por planta (number of fruits per plant); $\mathrm{MFF}=$ massa fresca média de frutos (average fruit fresh mass); ${ }^{2} \mathrm{~A}_{1 \mathrm{~N}}=0,12 \mathrm{~g} \mathrm{~m}^{-2} \mathrm{de} \mathrm{N} ; 0,23 \mathrm{~mL} \mathrm{~m}^{-2}$ de P e $0,11 \mathrm{~g} \mathrm{~m}^{-2}$ de $\mathrm{K}$ na fase vegetativa e $0,08 \mathrm{~g} \mathrm{~m}^{-2}$ de $\mathrm{N}, 0,045 \mathrm{~mL} \mathrm{~m}^{-2}$ de Pe $0,39 \mathrm{~g} \mathrm{~m}^{-2}$ de K para a fase reprodutiva $\left(\mathrm{A}_{1 \mathrm{~N}}=0.12 \mathrm{~g} \mathrm{~m}^{-2} \mathrm{~N} ; 0.23 \mathrm{ml} \mathrm{m}^{-2} \mathrm{P}\right.$ and $0.11 \mathrm{~g} \mathrm{~m}^{-2} \mathrm{~K}$, in the vegetative stage; and $0.08 \mathrm{~g} \mathrm{~m}^{-2} \mathrm{~N}, 0.045 \mathrm{ml} \mathrm{m}^{-2} \mathrm{Pe} 0.39 \mathrm{~g} \mathrm{~m}^{-2} \mathrm{~K}$, in reproductive stage); $\mathrm{A}_{0 \mathrm{~N}}=$ zero de $\mathrm{N} ; \mathrm{A}_{1 / 3 \mathrm{~N}}=$ $0,04 \mathrm{~g} \mathrm{~m}^{-2}$ de $\mathrm{N} ; \mathrm{A}_{2 / 3 \mathrm{~N}}=0,08 \mathrm{~g} \mathrm{~m}^{-2}$ de $\mathrm{N}$, mantidas as doses de $\mathrm{P}$ e $\mathrm{K}$, tanto para a fase vegetativa como para fase reprodutiva $\left(\mathrm{A}_{0 \mathrm{~N}}=\right.$ zero $\mathrm{N} ; \mathrm{A}_{1 / 3 \mathrm{~N}}=0.04 \mathrm{~g} \mathrm{~m}^{-2} \mathrm{~N} ; \mathrm{A}_{2 / 3 \mathrm{~N}}=0.08 \mathrm{~g} \mathrm{~m}^{-2} \mathrm{~N}$, keeping the same $\mathrm{P}$ and $\mathrm{K}$ rates in both the vegetative and reproductive stage).

março e, nas adubações $\mathrm{A}_{1 / 3 \mathrm{~N}}$ e $\mathrm{A}_{2 / 3 \mathrm{~N}}$, a partir dos dias 22 e 26 de março, respectivamente. Isso indica que a cultivar Seascape produziu menor número de estolões (Tabela 1), possibilitando a formação de maior número de inflorescências e, conseqüentemente, maior número de frutos (Tabela 1).

Para produtividade, número e peso médio de frutos não houve interação entre adubação e cultivar (Tabela 1), permitindo que o efeito das doses de $\mathrm{N}$ seja avaliado mediante a comparação de médias para cada cultivar separadamente. Para nenhuma destas características houve influência significativa das adubações testadas, indicando que o $\mathrm{N}$ não interferiu na fase reprodutiva da cultura quando se cultiva o morango em solos com características semelhantes àquelas do experimento.

Por outro lado, houve diferenças estatísticas entre as cultivares quando se avaliou as respostas de produtividade, número de frutos e peso médio de frutos. A cultivar Seascape foi mais pro- dutiva que a cultivar Aromas. Já a cultivar Diamante não diferiu estatisticamente das demais em relação à produtividade (Tabela 1). As produtividades alcançadas estiveram acima da média nacional (25 t ha-1) (Santos \& Medeiros, 2003), independente da adubação ou cultivar estudada. E, o mais importante é que essa produção ocorreu entre 13 de janeiro e 31 de maio, que corresponde ao período de pouca oferta de frutos de morango no mercado.

A maior produtividade apresentada pela cultivar Seascape em relação à cultivar Aromas está relacionada ao maior número de frutos por planta que esta cultivar produziu em relação às cultivares Diamante e Aromas (Tabela 1). Parte desse resultado é explicada pelo menor número de estolões e pelo menor período em que as plantas da cultivar Seascape permaneceram emitindo os estolões. Esse fato aumenta a possibilidade da emissão de inflorescências e, conseqüentemente, formação de frutos.

Entretanto, a maior quantidade de frutos produzidos pela cultivar Seascape resultou em menor peso médio de frutos em relação às outras cultivares (Tabela 1). Ainda assim, o valor médio de 12,2 g por fruto é considerado de ótima qualidade comercial. As cultivares Diamante e Aromas produziram estatisticamente o mesmo número de frutos por planta (Tabela 1). Porém, o peso médio dos frutos da cultivar Diamante foi significativamente maior que aquele da cultivar Aromas, embora ambas as cultivares tenham apresentado produtividade significativamente similar (Tabela 1).

Desta forma, observou-se que a produtividade está relacionada a duas características de cada cultivar: o peso médio de frutos e o número de frutos produzidos por planta ao longo do ciclo. O produtor poderá optar pelas características da cultivar que mais interessam ao mercado em que irá comercializar o morango. Isto é, sem prejuízo da produtividade, o produtor escolherá, por exemplo, entre as cultivares Seascape ou Diamante, se o consumidor tem preferência por frutos de menor ou maior tamanho, respectivamente.

No entanto, deve-se considerar que as respostas produtivas do morangueiro a diferentes níveis de $\mathrm{N}$ podem variar dependendo do tipo de solo a ser utilizado para o cultivo. Nesse experimento, a área cultivada apresentava $23 \mathrm{~g} \mathrm{dm}^{-3}$ de $\mathrm{C}$, o que permitiria estimar um solo com 0,15 a $0,19 \%$ do $\mathrm{N}$ total. Isso, se for considerado que para as condições dos Campos Gerais, no horizonte A de solos câmbicos, a relação C:N se encontra entre 1:12 e 1:15 (Sá et al., 2008) e que não há fator limitante para a mineralização da matéria orgânica do solo. Pode-se considerar que, em solos sob preparo na região dos Campos Gerais, a taxa de mineralização é de $3,3 \%$, o que daria valores entre 143 e $179 \mathrm{~kg} \mathrm{ha}^{-1}$ de $\mathrm{N}$ disponível. Essa faixa de valores estaria dentro do valor médio de $\mathrm{N}$ total absorvido pelo morangueiro que é de aproximadamente $120 \mathrm{~kg} \mathrm{ha}^{-1}$ (Muramoto et al., 2004) para cultivo de inverno. Por outro lado, a fertilização com $\mathrm{N}$ pode também não apresentar respostas produtivas para a cultura do morangueiro mesmo quando o solo apresenta concentração de matéria orgânica baixa, condição essa que contribuiria de maneira pouco expressiva para o requerimento total de $\mathrm{N}$ da 
cultura. Foi o caso do trabalho conduzido por Hochmuth et al. (1996) que testaram doses entre 0,28 e $1,4 \mathrm{~kg}$ de $\mathrm{N} \mathrm{ha}^{-1}$ $\mathrm{dia}^{-1}$ em dois experimentos em anos consecutivos para um solo com 1,0 g $\mathrm{kg}^{-1}$ de matéria orgânica. Para o primeiro experimento (1991-92), a produção total de frutos aumentou com o aumento das doses de $\mathrm{N}$ até $0,54 \mathrm{~kg}$ de $\mathrm{N}$ ha ${ }^{-1} \mathrm{dia}^{-1}$. No entanto, a fertilização com $\mathrm{N}$ não interferiu na produção do morango no segundo experimento (1992-93).

Assim, em relação às adubações avaliadas no presente trabalho, a Adubação $\mathrm{A}_{1 \mathrm{~N}}$ é aquela que tem sido recomendada para produtores de frutos no verão. Nesta formulação, a dose de nitrogênio é maior que nas demais, tanto para a fase vegetativa como para a reprodutiva do morangueiro. Como não ocorreram diferenças entre as adubações testadas, tanto para produtividade como para peso e número de frutos por planta, o produtor poderá optar pelas adubações que resultaram em menor custo. Entretanto, essa decisão só deverá ser tomada caso a área a ser cultivada apresente valores altos deste nutriente, como por exemplo, em solos onde foi realizada uma adubação orgânica adequada ou com características semelhantes ao solo desse experimento ( $23 \mathrm{~g}$ $\mathrm{dm}^{-3}$ de $\mathrm{C}$, sem impedimentos para a mineralização da matéria orgânica do solo). Estes resultados devem ser considerados para produção de frutos durante o período de verão, que apresenta menor ciclo produtivo (de janeiro a maio) em relação ao cultivo de inverno (maio a dezembro). É importante que seja conhecida a real necessidade de nutrientes durante o ciclo produtivo das cultivares de DN destinadas ao cultivo de verão. $\mathrm{O}$ ajuste adequado ou redução do uso de fertilizantes é parte importante de uma produção sustentável.

\section{AGRADECIMENTOS}

À empresa Bioagro pela concessão das mudas de morango e da bolsa de estudos para o acadêmico.

\section{REFERÊNCIAS}

CEASA/PR - Centrais de Abastecimento do Paraná. 2007, 23 de julho. Volumes comercializados nas unidades atacadistas. Disponível em http://celepar7.pr.gov.br/ ceasa/result_evolucao_das_unidades.asp.

EMBRAPA. 1999. Sistema brasileiro de classificação dos solos. Brasília: Embrapa. 412 p.

FERRARI RA; SOUZA WL; OLIVEIRA VS; SCABIO A; BARCARO P; OTTO RF. 2004. Avaliação físico-química e sensorial de três cultivares de morango. In: CONGRESSO BRASILEIRO DE CIÊNCIA E TECNOLOGIA DE ALIMENTOS, 19. Anais... Recife: SCCTA.

HOCHMUTH GJ; ALBREGTS EE; CHANDLER CC; CORNELL J; HARRISON J. 1996. Nitrogen fertigation requirements of drip-irrigated strawberries. Journal of American Society for Horticultural Science 121: 660-665.

MANAKASEM Y; GOODWIN PB. 2001. Responses of dayneutral and Junebearing strawberries to temperature and daylength. Journal of Horticultural Science and Biotechnology 76: 629-635.

MURAMOTO J; GLIESSMAN SR; SCHMIDA D; SHENNAN C; SWEZEY S. 2004. Nitrogen Dynamics in an Organic Strawberry Production System. In: CALIFORNIA ORGANIC PRODUCTION AND FARMING IN THE NEW MILLENNIUM: A RESEARCH SYMPOSIUM. Proceedings... California: The International House, University of California, Berkeley. p. 131-134.
PASSOS FA. 1999. Nutrição, adubação e calagem do morangueiro. In: DUARTE FILHO J; CANÇADO GMA; REGINA MA; ANTUNES LEC; FADINI MAM. (Coord.). Morango: tecnologia de produção $e$ processamento. Caldas, MG: Epamig. p. 159-167.

REICHERT LJ; MADAIL JCM. 2003. Aspectos socioeconômicos. In: SANTOS AM; MEDEIROS ARM (eds). Morango: produção. Embrapa Clima Temperado (Pelotas). Brasília: Embrapa Informação Tecnológica. p. 12-15. (Frutas do Brasil, 40).

SÁ JCM; SÁ MFM; SANTOS JB; OLIVEIRA A. 2008. Dinâmica da matéria orgânica nos Campos Gerais. In: SANTOS GA; SILVA LS; CANELLS LP; CAMARGO FAO (eds). Fundamentos da matéria orgânica do solo - ecossistemas tropicais e subtropicais. Porto Alegre: ed. Metrópoli. p. 443-461.

SANTOS AM; MEDEIROS ARM. 2003. Introdução. In: SANTOS AM; MEDEIROS ARM (eds.). Morango: produção. Embrapa Clima Temperado (Pelotas). Brasília: Embrapa Informação Tecnológica. p. 911. (Frutas do Brasil, 40).

SEAB/PR - Secretaria da Agricultura e do Abastecimento do Paraná - 2007, 23 de julho. Estimativa da área e da produção de frutas, no Paraná - Safras 00/01 02/ 03. Disponível em http:// www.seab.pr.gov.br/arquivos/File/deral/ efpr.xls.

TAGLIAVINI M; BALDI E; LUCCHI P; ANTONELLI M; SORRENTI G; BARUZZI G; FAEDI W. 2005. Dynamics of nutrients uptake by strawberry plants (Fragaria $\mathrm{x}$ ananassa Dutch.) grown in soil and soilless culture. European Journal of Agronomy, 23: 15-25.

TWORKOSKI TJ; BENASSI TE; TAKEDA F. 2001. The effect of nitrogen on stolon and ramet growth in four genotypes of Fragaria chiloensis L. Scientia Horticulturae, 88: 97-106. 